\title{
Construcción de paz en Colombia: Retos en el posacuerdo
}

\author{
Judith Miranda López*
}

Rico, D., \& Medina-Arboleda, I. F. (2020). Construcción de paz en el posacuerdo: avances, tensiones y desafios. Universidad del Norte, Universidad Católica de Colombia.

El 24 de agosto de 2016 se daba a conocer, desde La Habana, Cuba, el histórico anuncio de la culminación de los diálogos de paz entre el gobierno colombiano y la antigua guerrilla de las FARC-EP para poner fin a los más de cincuenta años de conflicto armado en Colombia. Desde esa fecha han pasado ya casi cuatro años, pero la implementación temprana del acuerdo final ha tenido que enfrentarse a varios retos que no solamente han entorpecido el proceso, sino que también constituyen una barrera hacia el camino de construir paz en el país.

Frente a este panorama, resulta imperativo ofrecer herramientas que propicien la construcción de ambientes de paz sostenibles y democráticos, y es en este orden de ideas que el libro Construcción de paz en el posacuerdo, de Rico Revelo y Medina-Arboleda, compuesto por ocho capítulos y publicado en Colombia, ofrece, a partir de definiciones, conceptos, teorías y metodologías, aportes significativos que buscan desvelar algunas de las barreras que más afectan la transición hacia una cultura de paz y no violencia.

Específicamente, en el primer capítulo de este libro se presenta el contexto de polarización política del país durante el proceso de refrendación popular del acuerdo de paz. Acá, se presenta el estudio del estilo lingüístico y el contenido de las publicaciones de algunos grupos políticos en la red social Twitter en la víspera del sometimiento popular de ratificación del acuerdo. En particular, este capítulo es un referente del clima de polarización que incluso en la actualidad vive Colombia, y que viene a ser una barrera cultural fundamental para la implementación de los acuerdos y la búsqueda de soluciones pacíficas al enfrentamiento con otros grupos armados, como el Ejército de Liberación Nacional (ELN).

Posterior a esto, en el segundo capítulo se esboza un panorama regional de los retos y perspectivas de la construcción de paz en el Caribe colombiano, lo cual se presenta a través de la realización de un estudio que da cuenta de dinámicas diferenciales de las apuestas por el desarrollo, y a partir de un enfoque de paz territorial en áreas rurales en las que históricamente han permanecido actores y mecanismos relacionados con el conflicto armado interno y el crimen organizado.

Después, en el tercer capítulo se evalúan los aportes a nivel educativo superior frente a la formación en competencias ciudadanas, por medio de un estudio que va en consonancia con la apuesta mundial para la formación en ciudadanía como una de las bases para la construcción de sociedades pacíficas, justas y equitativas.

También dentro del contexto educativo, y como apuesta de pedagogía para la paz, en el cuarto capítulo se explora la contribución de la didáctica activa en la evaluación del aporte a las competencias en las ciencias sociales. Aquí, la investigación da cuenta de los retos y desafíos del sistema educativo para transformar la manera en que la ciudadanía aborda el currículo.

Al finalizar esta parte, en el quinto capítulo se describe un estudio de microsociología política que deja en evidencia la importancia de fortalecer las competencias para la deliberación en términos de cultura de paz, con un contenido analizado desde una perspectiva de género que refleja la tendencia de las mujeres excombatientes a darle prioridad a la satisfacción de necesidades básicas en el momento actual — donde se enfrentan a la construcción de sus proyectos de vida- - y a experimentar tensiones entre la igualdad de género y el rol de la mujer desde un marco de referencia patriarcal.

Luego, en el sexto capítulo se presenta una importante reflexión sobre cómo avanzar hacia una cultura de paz en medio del escenario de transición que vive Colombia, pero ahora conociendo las experiencias de excombatientes acogidos a la Ley de Justicia y Paz, precisando lecciones aprendidas en la búsqueda de la reconciliación social con excombatientes de las FARC-EP, y cotejando los

\footnotetext{
* Politóloga egresada de la Universidad del Norte de Barranquilla, Colombia, auxiliar de investigación del Centro de Pensamiento en Construcción de Paz UNCaribe, y docente del Instituto Experimental del Atlántico.
} 
planteamientos de reconciliación social con el caso en particular; todo esto con el fin de plantear las bases para la formulación de políticas públicas en el posacuerdo.

$\mathrm{Y}$, finalmente, en los capítulos séptimo y octavo se exponen distintas investigaciones sobre el rol de colectivos civiles que se han organizado para pasar de una cultura de guerra a una cultura de paz, en consonancia con la carta de las Naciones Unidas sobre la construcción de un mundo diferente de la guerra y la militarización de la existencia para las generaciones venideras.

En conclusión, cada uno de los trabajos que componen el libro Construcción de paz en el posacuerdo es certero con los resultados que arroja y contribuye con gran relevancia al logro de una visión holística del panorama de la construcción de paz en Colombia. En general, esta obra resulta pertinente y hace un llamado a sus lectores para cooperar en la superación de cada reto que menciona, así como para considerar la construcción de la memoria histórica como un proceso que trasciende los nefastos efectos de la guerra.

\section{Referencias}

Adams, D. (2014). Cultura de Paz: Una utopía posible. Herder. UNESCO (2017). Educación para la ciudadanía mundial en América Latina y el Caribe: "Hacia un mundo sin muros: educación para la ciudadanía mundial en el ODS 4 Agenda E2030". UNESCO. 